\title{
Cognitive Control at Age 3: Evaluating Executive Functions in an Equitable Montessori Preschool
}

\author{
Jessica Phillips-Silver ${ }^{1 *}$ and María Teresa Daza ${ }^{2,3}$ \\ ${ }^{1}$ Department of Neuroscience, Georgetown University Medical Center, Washington, DC, United States, ${ }^{2}$ Department of \\ Psychology, University of Almería, Almería, Spain, ${ }^{3}$ Neuropsychological Evaluation and Rehabilitation Center (CERNEP), \\ University of Almeria, Almeria, Spain
}

\section{OPEN ACCESS}

Edited by:

Rocio Garcia-Carrion, Universitat de Lleida, Spain

Reviewed by: Matthew Peter Somerville, University College London, United Kingdom Laura Traverso,

University of Genoa, Italy

*Correspondence:

Jessica Phillips-Silver jsp102@georgetown.edu

Specialty section:

This article was submitted to Educational Psychology, a section of the journal Frontiers in Education

Received: 04 December 2017 Accepted: 14 November 2018 Published: 07 December 2018

Citation:

Phillips-Silver J and Daza MT (2018) Cognitive Control at Age 3: Evaluating Executive Functions in an Equitable Montessori Preschool. Front. Educ. 3:106 doi: 10.3389/feduc.2018.00106
Studies in cognitive neuroscience have shown that education practices can affect the development of executive functions (EF) in young children, although there is very little evidence on young preschool children. The present study aims to provide support for this endeavor, and consists of a quasi-experimental design with one-group pre-test/ post-test measures of cognitive control at age 3 in an urban public Montessori preschool. Three-year-olds $(N=23)$ in an authentic Montessori public preschool in Washington DC improved significantly on core EF measures (inhibitory control and cognitive flexibility) validated by the NIH Toolbox Early Childhood Cognition Battery, and the data revealed large effect sizes. Comparisons against $\mathrm{NIH}$ published norms revealed no selection bias. Performance on EF measures did not correlate with age but did correlate with amount of time between testing sessions, suggesting the possibility that experience, more than age, could have contributed to cognitive control growth. A controlled comparison between mixed-age and single-age classes revealed no differences in these EFs, raising the possibility that aspects of the environment other than the age composition are likely to contribute to growth. We propose that a potential contributor to EF growth is Montessori education, and more specifically, that this growth might be found in the design of interaction of the child with the environment. In particular, we discuss the design element called control of error, and consider why this element might be related to cognitive abilities such as inhibitory control. In current national discussions on the importance of equitable early childhood education, the synthesis of findings from neurocognitive studies has implications for children's academic and life success.

\section{Keywords: executive function, preschool, montessori, NIH toolbox cognition battery, equity}

\section{INTRODUCTION}

In recent years, the field of cognitive neuroscience has seen a great interest in understanding the role of executive functions (EF) in early child development, the mechanisms by which they develop, and the ways in which EF abilities can transfer across a variety of cognitive, emotional and social domains. Various empirical studies provide support for the idea that certain approaches to child education are well-equipped to instigate EFs and bolster their continued development over time. As this field of investigation grows, fascinating questions remain, including, from what age these $\mathrm{EF}$ abilities might be measured with respect to school experience, and what specific features of the 
educational approach are likely to foster strong development of EF. With these points of inquiry in mind, the aims of the current paper are: (1) to highlight several empirical studies which specifically address the role of focused educational approaches in supporting cognitive EF development-which we refer to here as cognitive control-in children, (2) to present a small, quasiexperimental study which lends support for this endeavor by demonstrating the feasibility of testing children as young as 3 years of age in the context of a public Montessori environment using the validated NIH Toolbox, and (3) to suggest a design feature particular to Montessori education that is consistent with the literature, and that we think is a promising avenue for future empirical investigation in children from a very young age.

Pioneering scientific work over recent years has demonstrated that the child that has cognitive control is a child that can learn and thrive in the school environment and in life (e.g., Blair and Diamond, 2008). For example, Diamond and colleagues have reported improvements in inhibitory control, working memory and cognitive flexibility in 5-year-old children in their second year of a school using the curriculum Tools of the Mind (Diamond et al., 2007). Tools of the Mind, which is based on the philosophy of Lev Vygotsky, is an educational approach that is designed around evidence-based teaching "tools" including intentional dramatic play, student-guided plans for play and learning, and instructional interactions among students and with their teachers (Bodrova and Leong, 2005). Diamond and colleagues argued, given the success of training EFs in 4- to 5-year-olds, that preschool is not too young to improve these abilities, and they stress the importance of the play-based curriculum, the repetitive practice of planning skills, and adaptive levels of challenge for students in this educational approach (Diamond et al., 2007).

From the perspective of another educational tradition, Lillard and colleagues reported enhanced EFs in children aged 512 years in a Montessori school, which developed out of the work of Maria Montessori (Lillard and Else-Quest, 2006). The Montessori approach has a focus on the principles of the "prepared environment"-in which the design of the young children's learning space allows independent work and discovery; the "prepared adult" - which refers to the classroom guide who is trained to optimally support the child's independent work and growth; and unique learning materials that are designed for the child to learn practical life skills, sensory development, literacy and math competence, and cultural appreciation (Montessori, 1988/1914). Of utmost importance to the Montessori approach is the central premise that with the proper support from environment, the adult and the appropriate materials, the child is capable of developing himself (Montessori, 1995/1949).

Both of the aforementioned studies revealed strong effects of public school curricula that were designed to foster EFs, and both measured performance of public school children from the age of 5 years. Two important questions for this field of research are: what are the core-and possibly common-elements of these educational approaches that show evidence of supporting $\mathrm{EF}$ growth, and from what age can we systematically measure improvements in EFs in the context of the full-time public school environment?
A common theme between these two educational approaches is the placement of the individual child at the center of the planning and decision-making process with respect to her own learning, and the role of the teacher as a guide to observe and support the child, rather than direct her, in her work. Barker and Munakata (2015a) discuss the importance of self-direction in developing EF, and consider the activation of goals as a potential key to the mastery of EFs such as inhibitory control (Barker and Munakata, 2015b). The findings from these studies suggest that the opportunity for a child to be self-driven, with an internalized goal, results in behaviors that reveal greater EF.

What about the Montessori approach, in particular, allows the opportunity for constant self-directed activity with internalized goals? One of the most unique features of the Montessori environment is the design of interaction of the child with environment, materials, and community-which has at its heart the goal of development of individual control and mastery. Within this design is a significant element, called "control of error," which refers to the instant sensory feedback which the child receives about her actions and predictions, and it pervades multiple levels of the environment-from the design of the classroom environment itself, to the learning materials, and the relationship with the guide (teacher) and students (Montessori, 1962/1948, 1995/1949). The learning materials are self-correcting, meaning that the child requires no external feedback to know whether he has successfully used or completed a material. The materials are required to be concrete, sensory objects whose proper physical manipulation allows for the immediate, sensory recognition of error, and self-correction. There are requirements not only regarding the material itself but also regarding its use, in order to protect the interest and concentration of the child who chose to use it (for a description see Marshall, 2017). With these specially designed materials and rules of engagement, the child is allowed to pursue her own spontaneous work and receive the necessary feedback-the control of error-that allows for her own maximal cognitivemotor growth. This contributes to the refinement and integration of the senses-for example, via the eye (e.g., the pink tower for learning weight and proportion), the ear (i.e., the bells for learning musical intervals), the hand (e.g., the sandpaper letters for handwriting preparation) or the whole body (i.e., the ellipse for walking, skipping). Furthermore, the Montessori classroom environment is designed and prepared with a deliberate selection, arrangement and limited availability of these learning materials which require constant cognitive control to use. The limited availability of materials (only one of each kind) resembles real life resource distribution and necessitates communal cooperation, patience and sharing-skills which enhance self-control. This distribution is also taken into account in the makeup of the students' community by age: the traditional mixed-age groups (3-6 years in the primary classroom) allow for younger children to observe and model older children in their use of the materials. The act of mentoring can occur naturally through the appropriate use of a material that the younger child has not yet mastered. In this sense, the relationships and cooperative work among children of different ages allow for opportunities to observe self-correction and mastery independently of the adult. 
The Montessori guide is prepared in his primary role which is to observe the child, and to allow her to pursue her own work and interaction with the environment and her community, with the goal of supporting that child's own cognitive-motor growth including physical exploration of the materials and activities in the environment. The guide is trained not to interfere with the child's natural and spontaneous work, nor her mastery of herself and her environment and materials; rather, the guide observes and provides support to the child specifically when necessary and valuable. The guide presents lessons on the materials but the child selects and carries out her own work goals on a given day or work cycle, learning from the very start that the work of her mind and body is her own, and is a reflection of her cognitive and motor control. This is not only a source of independence and freedom to learn, but a source of great pride for the child. Thus, the element of control of error pervades the relationship between the child and guide, and cannot be separated from the curricular method as it describes the fundamental structure and functioning of the classroom community, and the children's work within it.

Based on the strong theoretical background of Montessori education, its wealth of relevant evidence from neurocognitive research, and its increasing visibility in the public sector-and thus, potential to affect high-need or high-risk children-we propose a focus on testing EFs in school children from as young as 3 years of age. The preschool age is of great interest among researchers in cognitive, emotional, and motor development, and there is a great opportunity for demonstrating significant and reliable improvement in EFs at this age (e.g., Lillard et al., 2017). The development that occurs during the preschool agespecifically, before 5 years-is tremendous, including for example cognitive and motor changes that occur inextricably and in interaction (Diamond, 2000; Rueda et al., 2004; Haywood and Getchell, 2014). Changes in EF are known to rely particularly on the dorsolateral prefrontal cortex and its interaction with subcortical structures including cerebellum (Diamond, 2000; Rueda et al., 2004), and support the kind of sensorimotor control and integration that enables discrimination, planning, decision making and action (Kim and Shadlen, 1999; Rauschecker, 2011). With the joint maturation of motor-cognitive development come the abilities for independence in the child, and this can lay the foundation for developing cognitive control. Thus, there is a strong rationale for measuring EFs by age 3 (see also Bierman and Torres, 2016), and observing the development in core processes in a supportive educational environment.

The NIH Toolbox measures core EFs between the ages of 3 and 8 years via the Early Childhood Cognition Battery (ECCB) (Weintraub et al., 2013). The battery was designed to permit comparisons across a wide age range (the same core EF measures are utilized in the NIH Toolbox with individuals up to 85 years of age), and, importantly for very young or old populations, to provide replicable computer-based measures of EF that are not inhibited by differences in motor development or functioning (e.g., Victorson et al., 2014). From data collected in diverse populations of young children across the US in two languages (English and Spanish), two subtests were determined by the NIH authors to be the most robust and reliable indicators of EFs at this age: inhibitory control, as measured by the Flanker task, and cognitive flexibility, as measured by the Dimensional Change Card Sort task (Zelazo et al., 2013). Furthermore, inhibitory control (i.e., planning, error detection, novelty, and conflict processing) is considered to reflect effortful control of attention (Fan et al., 2002) and its associated executive attention network including target areas of the ventral tegmental dopamine system such as the anterior cingulate cortex and lateral prefrontal cortex (Bush et al., 2000; Botvinick et al., 2001; Benes, 2003; Matsumoto and Tanaka, 2004).

No study to our knowledge has implemented the NIH Toolbox in order to assess changes in executive functioning in the context of preschool experience. In the present study, we implemented core EF measures from the ECCB in an urban, lottery-based, public Montessori primary (preschool) setting (at the beginning and the end of the first school year). We aimed to demonstrate the feasibility of measuring changes in inhibitory control and cognitive flexibility from age 3 in this preschool context. We also aimed to observe whether improvements in executive functioning could be due in part to the mixed-age class structure of the Montessori school (with children ranging from 3 to 6 years of age in the primary classroom). In a unique opportunity presented as this school was expanding in size and had just begun a new classroom of only 3 -year-olds (in keeping with authentic Montessori protocol), we were able to observe this by comparing performance between two mixed-age classrooms (3 to 6-year-olds) and a single age classroom (3-year-olds only). This growing school, with its small size, provided the opportunity to successfully implement the NIH Toolbox measures in 3-year-olds, describe EF improvements observed, and suggest from the current data a rationale for future investigation of cognitive control in preschool.

\section{METHOD}

\section{Participants}

Participants were 23 healthy children (10 females), with no known developmental or neurological deficits, who were 3 years of age (mean age in months $=39.56 \mathrm{SD}=3.91$ at the start of the study). Participants varied in racial and ethnic descriptors (26\% African American, 52\% European American, 9\% Hispanic, $13 \%$ mixed race). One child was excluded because of a failure to cooperate due to tiredness. All children were in their first year of preschool at Shining Stars Montessori Academy in Washington DC, a lottery-based public charter school, which is accredited by the American Montessori Society and one of the country's very few accredited public Montessori institutions. The sample included children from three different primary classrooms at the school, each of which had a classroom of 20-25 children, led by one guide and one assistant, both of whom were trained either by the Association Montessori Internationale or the American Montessori Society). Families were recruited by flyers presented at the front desk of the school. Parents gave written informed consent for their children's participation and children received a personalized junior scientist certificate. 


\section{Materials and Methods}

The materials for the assessment of early childhood executive function included developmentally appropriate versions of the Flanker test and the Dimensional Change Card Sort test as developed for the NIH Toolbox ECCB (Weintraub et al., 2013). These measures were selected because they had been previously validated, were accessible and easily replicable, as well as available for testing populations in two languages (English and Spanish).

The Flanker test of inhibitory control and attention is derived from the Child Attention Network Test (Rueda et al., 2004), which measures the ability to inhibit visual attention to irrelevant information while performing a stimulus conflict task. On each of 40 trials, a central target (a yellow fish), pointing toward the right or left, is flanked by similar fish stimuli, pointing either in the same (congruent) or opposite (incongruent) direction. The child's task is to indicate the direction in which the central fish in the target array was pointing (for task figures and examples, see Rueda et al., 2004).

The Dimensional Change Card Sort test, designed to measure set shifting in children, requires matching stimuli according to the shifting dimensions of shape and color. The child DCCS test derives from the Wisconsin Card Sorting test, and has been shown to be an appropriate measure of task switching in preschool age children (e.g., Diamond, 2005). In this test, the first block presents trials in which only one dimensioni.e., color-is relevant, and then a second block in which the relevant dimension switches-i.e., to shape. Those who succeed in following the switch from the first to the second dimension also receive a mixed-dimension block, in which color is relevant on the majority of trials with occasional, unpredictable shifts to shape. The relevant criterion word, "color" or "shape," is delivered at the start of each trial, visually in the center of the screen, and simultaneously as an auditory spoken voice via the computer program. This task also consists of 40 trials.

These cognition domain measures were developed by NIH Toolbox, validated (using expert panels for content development and validation, cognitive interviews, small- and large-scale pilot testing) and developed for psychometric features (internal consistency and test-retest reliability, convergent and divergent validity) (Weintraub et al., 2013). Full details on the Flanker and DCCS tests are described by Weintraub et al. (2013), and in the Cognition Technical Manuals (http://www.healthmeasures. net/2-uncategorised/209-nih-toolbox-technical-manuals-forac). Scoring for both Flanker and DCCS measures in the NIH Toolbox ECCB were based on a combination of accuracy and reaction time, where each of these "vectors" ranged in value between 0 and 5, and the "computed score," combining each vector score, ranged from 0 to 10 . If accuracy for any given individual was $\leq 80 \%$, the final computed score was equal to the accuracy score; if accuracy was $>80 \%$, the reaction time score and accuracy score were combined. In this version of the tests, data from incongruent trials were specifically used as a measure of inhibitory control in the context of visual selective attention-which the authors determined could also be considered a measure of executive attention (but see Rueda et al., 2004 for alternative scoring methods; Zelazo et al., 2013).
According to these authors, a change in participants' scores between Time 1 and Time 2 represents a real change in the level of performance for each individual since the prior assessment.

NIH Toolbox conducted a national standardization study in English and Spanish languages to provide normative data for each assessment. This was based on a large sample of 4,859 participants, from the age of 3-85, and was representative of the U.S. population based on gender, ethnicity, race, and socioeconomic status. For the purpose of the present study, we excluded from the normative data sample any individual children who were identified as attending a Montessori School. Specifics regarding NIH Toolbox norming sampling methods and norming analytic can be found in Beaumont et al. (2013).

\section{Procedure}

The NIH Toolbox ECCB was implemented in accordance with the procedures and guidelines of the National Institutes of Health and Northwestern University (for test battery and technical manuals see www.nihtoolbox.org).

Children were tested twice: once at the start of the school year (T1), and again near the end of the school year (T2). The time elapsed between $\mathrm{T} 1$ and $\mathrm{T} 2$ was 211 days on average (SD $=33$ ). During testing children sat at a preschool desk in one of the classrooms outside of school hours. The tasks were presented as games on a computer screen with external speakers, and responses recorded using the computer keyboard and mouse. The entire session, including instructions and breaks, lasted $\sim 45 \mathrm{~min}$. Children took breaks as needed during testing, and parents sat quietly in the same room, on a chair at the wall behind the child.

\section{RESULTS}

We measured the degree of change in the scores on both tasks from T1 to T2. In the flanker task, a Wilcoxon analysis revealed highly significant improvement in scores across all 3-year-olds $(N=23)$ from an average score of $1.91(\mathrm{SD}=1.01)$ at $\mathrm{T} 1$ to $3.1(\mathrm{SD}=1.44)$ at T2 $(Z=-3.44, p=0.001)$, and an effect size analysis yielded a large effect size $(r=0.72)$. In the DCCS task, a Wilcoxon revealed highly significant improvement from a mean of $1.27(\mathrm{SD}=1.45)$ at $\mathrm{T} 1$ to $2.95(\mathrm{SD}=1.73)$ at $\mathrm{T} 2(Z=-3.9, p$ $=0.000)$, and the effect size was robust $(r=0.81)$ (see Figure 1).

We next compared the results of the Montessori 3-yearolds at $\mathrm{T} 1(N=23)$ with the NIH published norms of 3 year-old children who were attending schools unselected for curriculum or educational method (data provided by NIH). A Mann-Whitney test revealed no difference in either the Flanker task between the scores of Montessori children at T1 and Norms $(N=40$; mean $=1.68, \mathrm{SD}=0.72)$, or the DCCS task between Montessori children at $\mathrm{T} 1$ and Norms $(N=48$; mean $=1.39$, $\mathrm{SD}=1.5)$.

In order to test whether the degree of improvement among children depended upon their level of performance at first test, we divided all Montessori children $(N=23)$ into two groups, falling above or below a median score at $\mathrm{T} 1$. We found no significant difference in either the flanker score or the DCCS score at T2 

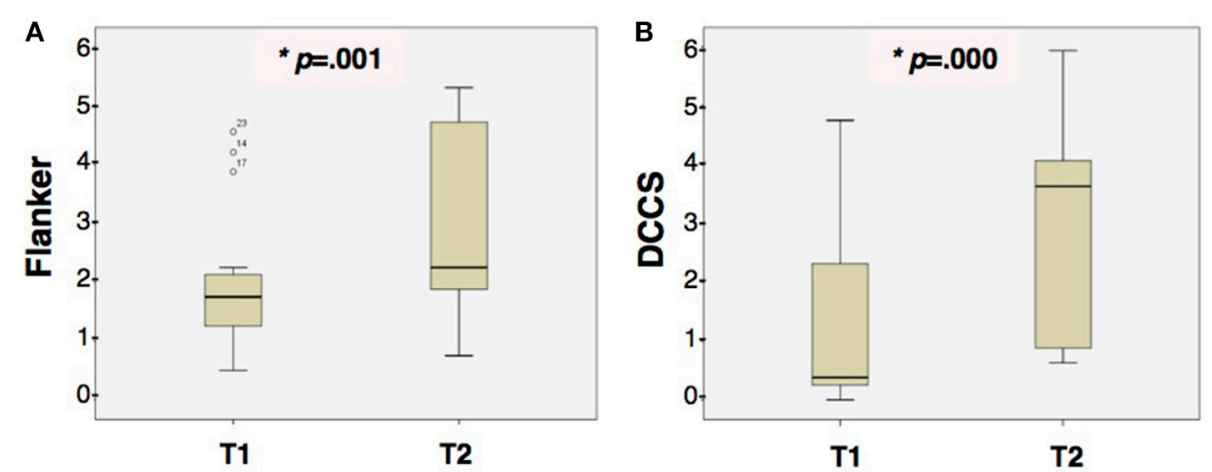

FIGURE 1 | Boxplots of the data of Montessori children $(N=23)$ across their first school year. Results show $(\mathbf{A})$ the Flanker task at T1 and T2, and (B) the DCCS task at T1 and T2. Error bars represent the standard deviation of the mean.

based on whether the children's scores at T1 fell above or below the median.

An examination of the demographic characteristics of the children showed no significant Pearson correlation between the improvement in Flanker and DCCS scores and any of the following factors: age, sex (via Mann-Whitney test), or racial or ethnic descriptors of the children. Rather the time elapsed (in days) from $\mathrm{T} 1$ to $\mathrm{T} 2$ was the only factor correlating with improvement in scores in the Flanker task $(r=0.44, p=0.038)$, and in the DCCS $(r=0.55, p=0.006)$.

We next examined the features that differed between the Montessori classrooms. A Mann-Whitney test showed no significant difference between EF scores and the children's specific classroom-i.e., the guide, or teacher. Finally, contrary to our prediction, a Mann-Whitney test showed no significant difference between EF scores and the type of classroom by agei.e., mixed age (3-6s) vs. single age ( 3 s only).

\section{DISCUSSION}

We implemented, for the first time, tests of core executive functioning from the NIH Toolbox Early Childhood Cognition Battery-inhibitory control and cognitive flexibility-to 3-yearolds during their first year of preschool in an authentic urban, public Montessori primary environment. Results showed highly significant improvements in scores on the Flanker and the DCCS tasks in children who were 3 years of age throughout the academic year, with significant effect sizes.

When compared with the published norms for these same tasks, taken from preschool children of the same age who were attending schools unselected for curriculum, the Montessori children obtained scores that were equivalent to the norms at the start of the school year. This suggests that the children in the present study were not, due to some unseen selection bias, different from the general population as measured by the NIH Toolbox.

In contrast with the findings of Diamond and colleagues with the Tools of the Mind program (Diamond et al., 2007), we did not find a significantly higher degree of improvement in children with lowest EF scores at first testing (see also Weibe et al., 2011; Blair and Raver, 2014). Rather, we found equal improvement in subgroups of children with high and low initial EF scores. This contrast may be due to the difference in testing EFs at age 4 or 5 (Diamond et al., 2007) vs., in the present study, at age 3, given the large degree of development that occurs between those ages (Diamond, 2000). Alternatively, the difference could reflect some feature that varies between the Tools of the Mind and Montessori programs, a point that would require further investigation.

Improvement in EFs did not correlate with the present children's age, sex or racial or ethnic descriptors; this is in contrast with previous reports (Akshoomoff et al., 2014). Rather the time elapsed between T1 and T2 predicted the level of EF growth. Since improvement depended upon amount of time but not age, and since the effect sizes were large, we interpret that the improvements were beyond those attributable to maturation from age per se, and that the key factor promoting the improvement is the amount of experience in the Montessori environment.

It is important to note that there are numerous ways to measure EF components (see Bierman and Torres, 2016), including measures that are not computerized but are based in physical body movement (e.g., the head-toes-knees-shoulders task) which may indeed be more suitable for very young children (McClelland et al., 2014). Furthermore, there is not always agreement about what defines executive functioning and how it is to be measured-Weibe et al. (2011) argue that at age 3 specifically, EF is a unitary, domain-general process which is best captured by a single EF construct. This raises caution in the use and interpretation of various component measures of EF such as those comprising the NIH Toolbox ECCB.

The most significant limitation of the present study was the lack of a control group from a comparison preschool program, as has been done in previous work on this topic (e.g., Lillard and Else-Quest, 2006). In order to fully explain the effects of Montessori experience on development of cognitive control at the preschool age, future investigations with control groups from non-Montessori programs are needed. Our primary aim with the present study was to use the recently established normative data from the NIH to make predictions about performance 
on developmentally appropriate cognitive control tasks in the preschool age range, and to measure the performance of 3year-olds in a public Montessori school against those norms. A second important limitation is the small sample size, which must be taken into account when interpreting both correlational and effect size data. In order to fully attribute gains in EF to the Montessori school environment, and their relation to demographic and school choice factors, future studies on a larger scale must consider a control group with sufficient variability to allow for reliable correlational data and interpretation.

A fortuitous opportunity allowed for us to address our secondary aim in this study: a controlled comparison between mixed-age and single-age classes within the same Montessori environment, as a new classroom (of only 3-year-olds) was just established in the school at the start of the experiment. We reiterate that the small sample size means the data must be interpreted with caution. In contrast with our prediction, EF scores were not significantly different between the mixedage and single-age classes. This could suggest, first, that the effects of the mixed-age classroom (which include younger children imitating the behavior of older classmates, and more mature children presenting lessons and assistance to less mature ones), may not be captured by measures of "cool executive functions"-i.e., cognitive executive functions, such as the flanker and card sorting tasks, but rather by measures of "hot executive functions" such as social and emotional functioning (Zelazo and Carlson, 2012). Second, and more importantly for the present discussion, the lack of significant difference in cognitive EFs between the mixed-age and single-age classrooms in this study suggest that the age range was not a contributor to the growth in this context. Instead, it more likely points to the possibility of the Montessori curriculum-which was constant across classrooms-as a source of improvement in inhibitory control and cognitive flexibility. The more experience children had in the Montessori environment, the greater was their improvement on EF scores, a finding which again would be consistent with the idea that the Montessori curricular method is accountable for developing cognitive control. This result is consistent with findings by Lillard (2012) regarding the fidelity of implementation of Montessori, in which a regression analysis showed that an improvement on one EF measure (headshoulders-knees-toes task) in young children enrolled in halfor full-day private schools were predicted by the percentage of children in the classroom who were using Montessori, rather than non-Montessori, materials.

Various activities are known to contribute to the healthy development of EFs between the ages of 4 and 12 years, including music and mindfulness, sports and martial arts, and specifically designed school curricula (i.e., Montessori and Tools of the Mind). One of those can impact the majority of a child's waking hours during the week, is guided by public policy, and by necessity impacts cognitive and motor growth and overall wellbeing: the public school environment.

For the benefit of future research, we suggest that the design element "control of error" be examined as a potential causal factor in the success of Montessori educational environments. It is possible that various environments and activities implement some variation of this feature, in that the learning material or activity provides the opportunity, or even the requirement, for a child to perceive the feedback of her own thought or action and to adjust it in appropriate ways which can be interpreted and used to refine behavior without necessitating direction or interference from an adult. Control of error is central to the design of the early primary Montessori curricular method and can be considered paramount to later intellectual development (Diamond, 2012; Marshall, 2017). At the root of the element of control of error is, precisely, the development of self-mastery and cognitive control.

According to Montessori, self-mastery and cognitive control are the very core of the young child's desire and effort: by learning to regulate his own thoughts and actions-with the appropriate guidance and scaffolding - the child develops a pleasing sense of self-mastery and mastery of his environment (e.g., Montessori, 1995/1949). Recent research suggests that the most important predictor of academic and life success is executive functioning (Blair and Razza, 2007; Moffitt et al., 2011; Coldren, 2013; Zelazo et al., 2013; Mann et al., 2017). Schools implementing curricula designed to promote EF show this effect (Diamond, 2000, 2012; Lillard and Else-Quest, 2006; Diamond et al., 2007; Blair and Raver, 2014), and the fidelity of implementation of curriculum matters (Lillard, 2012). And while various practicebased activities, such as music and sports, are known to improve EFs (Diamond, 2012; Skoe and Kraus, 2012), some speciallydesigned training programs do not result in improvement on core EFs such as inhibitory control (Thorell et al., 2009; but see also Traverso et al., 2015), suggesting that more than a focused training program is required for growth. Bierman and Torres (2016), in a detailed comparative review, have argued that while short term interventions warrant investigation, they may not provide the broad approach required to produce long-lasting abilities in EF. Further research with proper control groups is needed to demonstrate how and to what extent the Montessori environment, and possibly the aspect of control of error, can affect the development of cognitive control. The findings of the present study, though limited, are consistent with the idea that a developmentally sensitive school curriculum can nurture the desired growth in EFs, and that this growth can be measured by the validated and replicable NIH Toolbox even from the tender age of 3 years. These results point to the need for further empirical study, as they may have important implications for the implementation of Montessori in the public sector, and its philosophy regarding the education of EFs beginning by age 3 .

Researchers have cautioned that the practice of EFs may avert widening achievement gaps later (Diamond and Lee, 2011) and prevent school failure (Blair and Diamond, 2008). This is a call to action echoing Montessori's life work (Montessori, 1962/1948, 1995/1949; Lillard, 2005), and the availability of preschool programs including Montessori can allow for the practice of EFs to be pervasive to the child's daily experience by age 3 . Concerns in the public education system regarding achievement gaps in EFs due to individual differences in learning, poverty or privilege, or other cognitive, social, and economic factors that are known to impact learning and life success (Mani et al., 2013; Blair and Raver, 2016) point to the development of EF in equitable school environments. The Montessori curriculum 
is a subject of increasing research, and has been shown to be effective across various measures of educational performance and throughout childhood (Lillard, 2012). This approach reflects a curriculum-and a philosophy of the child's life and mind-which warrants further investment from science and society.

\section{"Il bambino è padre dell'umanità e della civilizzazione, è il nostro maestro, anche nei riguardi della sua educazione." ["The child is the father of humanity and of civilization; he is our teacher, even with regard to his education."]}

-Montessori, 1949

\section{ETHICS STATEMENT}

This study was carried out in accordance with the recommendations of the Bioethics Committee for Human Research at the University of Almeria with informed consent from all subjects. All subjects gave written informed consent in

\section{REFERENCES}

Akshoomoff, N., Newman, E., Thompson, W. K., McCabe, C., Bloss, C. S., Chang, L., et al. (2014). The NIH toolbox cognition battery: results from a large normative developmental sample (PING). Neuropsychology 28, 1-10. doi: 10.1037/neu0000001

Barker, J. E., and Munakata, Y. (2015a). Developing self-directed executive functioning: recent findings and future directions. Mind Brain Educ. 9, 92-99. doi: $10.1111 / \mathrm{mbe} .12071$

Barker, J. E., and Munakata, Y. (2015b). Time isn't of the essence: activating goals rather than imposing delays improves inhibitory control in children. Psychol. Sci. 26, 1898-1908. doi: 10.1177/0956797615604625

Beaumont, J. L., Havlik, R., Cook, K. F., Hays, R. D., Wallner-Allen, K., Korper, S. P., et al. (2013). Norming plans for the NIH toolbox. Neurology 80(11 Suppl. 3), S87-S92. doi: 10.1212/WNL.0b013e3182872e70

Benes, F. M. (2003). Emerging principle of altered neural circuitry in schizophrenia. Brain Res. Rev. 31, 251-269. doi: 10.1016/S0165-0173(99)00041-7

Bierman, K. L., and Torres, M. (2016). Executive Function in Preschool Age Children: Integrating Measurement, Neurodevelopment and Translational Research. eds J. A. Griffin, L. S. Freund, and P. McCardle. Washington, DC: American Psychological Association.

Blair, C., and Diamond, A. (2008). Biological processes in prevention and intervention: the promotion of self-regulation as a means ofpreventing school failure. Dev. Psychopathol. 20, 899-911. doi: 10.1017/S0954579408000436

Blair, C., and Raver, C. C. (2014). Closing the achievement gap through modification of neurocognitive and neuroendocrine function: results from a cluster randomized controlled trial of an innovative approach to the education of children in kindergarten. PLOS ONE 9:e112393. doi: 10.1371/journal.pone.0112393

Blair, C., and Raver, C. C. (2016). Poverty, Stress, and Brain Development: new directions for prevention and intervention. Acad. Pediatr. 16(3 Suppl):S30-S36. doi: 10.1016/j.acap.2016.01.010

Blair, C., and Razza, R. P. (2007). Relating effortful control, executive function, and false belief understanding to emerging math and literacy ability in kindergarten. Child Dev. 78, 647-663. doi: 10.1111/j.1467-8624.2007.01019.x

Bodrova, E., and Leong, D. J. (2005). High quality preschool programs: what would Vygotsky say? Early Educ. Dev. 16, 435-444. doi: 10.1207/s15566935eed1 604_4

Botvinick, M. M., Braver, T. S., Barch, D. M., Carter, C. S., and Cohen, J. C. (2001). Conflict monitoring and cognitive control. Psychol. Rev. 108, 624-652. doi: 10.1037/0033-295X.108.3.624 accordance with the Declaration of Helsinki. The protocol was approved by the Bioethics Committee for Human Research.

\section{AUTHOR CONTRIBUTIONS}

JP-S and MD designed the experiment, collected and analyzed data, and wrote the manuscript.

\section{ACKNOWLEDGMENTS}

The authors wish to acknowledge the National Institutes of Health and Northwestern University for providing open access to and support for the NIH Toolbox, to promote research on the development of executive functioning across the lifespan. We thank Dr. Nathan Fox and Montessori Guide Autumn Wilson for helpful discussions. We are grateful to the participating families, and the founders, leadership and staff of the fully accredited Shining Stars Montessori Academy, who are a model of quality education and social justice.

Bush, G., Luu, P., and Posner, M. I. (2000). Cognitive and emotional influences in anterior cingulate cortex. Trends Cogn. Sci. 4, 215-222. doi: 10.1016/S1364-6613(00)01483-2

Coldren, J. T. (2013). Cognitive control predicts academic achievement in kindergarten children. Mind Brain Educ. 7, 40-48. doi: 10.1111/mbe.12006

Diamond, A. (2000). Close interrelation of motor development and cognitive development and of the cerebellum and prefrontal cortex. Child Dev. 71, 44-56. doi: 10.1111/1467-8624.00117

Diamond, A. (2005). Preschool children's performance in task switching on the dimensional change card sort task: separating the dimensions aids the ability to switch. Dev. Neuropsychol. 28, 689-729. doi: 10.1207/s15326942dn2802_7

Diamond, A. (2012). Activities and programs that improve children's executive functions. Curr. Dir. Psychol. Sci. 21, 335-341. doi: 10.1177/0963721412453722

Diamond, A., Barnett, W. S., Thomas, J., and Munro, S. (2007). Preschool program improves cognitive control. Science 318, 1387-1388. doi: $10.1126 /$ science. 1151148

Diamond, A., and Lee, K. (2011). Interventions shown to aid executive function development in 4 to 12 years old. Science 333, 959-963. doi: $10.1126 /$ science. 1204529

Fan, J., McCandliss, B., Sommer, T., Raz, A., and Posner, M. I. (2002). Testing the efficiency and independence of attentional networks. J. Cogn. Neurosci. 14, 340-347. doi: 10.1162/089892902317361886

Haywood, K., and Getchell, N. (2014). Life Span Motor Development. Champaign, IL: Human Kinetics Press.

Kim, J. N., and Shadlen, M. N. (1999). Neural correlates of a decision in the dorsolateral prefrontal cortex of the macaque. Nat. Neurosci. 2, 176-185. doi: $10.1038 / 5739$

Lillard, A., and Else-Quest, N. (2006). The early years: evaluating Montessori education. Science 313, 1893-1894. doi: 10.1126/science.1132362

Lillard, A., Heise, M. J., Richey, E., M., Tong, X., Hart, A., et al. (2017). Montessori preschool elevates and equalizes outcomes: a longitudinal study. Front. Psychol. 8:1783. doi: 10.3389/fpsyg.2017.01783

Lillard, A. S. (2005). Montessori: The Science Behind the Genius. New York, NY: Oxford University Press.

Lillard, A. S. (2012). Preschool children's development in classic Montessori, supplemented Montessori, and conventional programs. J. Sch. Psychol. 50, 379-401. doi: 10.1016/j.jsp.2012.01.001

Mani, A., Mullainathan, S., Shafir, E., and Zhao, J. (2013). Poverty Impedes Cognitive Function. Science 341, 976-980. doi: 10.1126/science.12 38041

Mann, T. D., Hund, A. M., Hesson-McInnis, M. S., and Roman, Z. J. (2017). Pathways to school readiness: executive functioning predicts academic and 
social-emotional aspects of school readiness. Mind Brain Educ. 11, 21-31. doi: $10.1111 / \mathrm{mbe} .12134$

Marshall, C. (2017). Montessori Education: a review of the evidence base. NPJ Sci. Learn. 2:11. doi: 10.1038/s41539-017-0012-7

Matsumoto, K., and Tanaka, K. (2004). Neuroscience. Conflict and cognitive control. Science 303, 969-970. doi: 10.1126/science.1094733

McClelland, M. M., Cameron, C. E., Duncan, R., Bowles, R. P., Acock, A. C., Miao, A., et al. (2014). Predictors of early growth in academic achievement: the headtoes-knees-shoulders task. Front. Psychol. 5:599. doi: 10.3389/fpsyg.2014.00599

Moffitt, T. E., Arseneault, L., Belsky, D., Dickson, N., Hancox, R. J., Harrington, H., et al. (2011). A gradient of childhood self-control predicts health, wealth, and public safety. Proc. Natl. Acad. Sci. U.S.A. 108, 2693-2698. doi: $10.1073 /$ pnas. 1010076108

Montessori, M. (1949). Lecture III. San Remo: The San Remo Lectures.

Montessori, M. (1962/1948). The Discovery of the Child. Madras: Kalakshetra Publications.

Montessori, M. (1988/1914). Dr. Montessori's Own Handbook. New York, NY: Schocken; Knopf Doubleday.

Montessori, M. (1995/1949). The Absorbent Mind. New York, NY: Henry Holt.

Rauschecker, J. (2011). An expanded role for the dorsal auditory pathway in sensorimotor control and integration. Hear. Res. 271, 16-25. doi: 10.1016/j.heares.2010.09.001

Rueda, M. R., Fan, J., McCandliss, B. D., Halparin, J. D., Gruber, D. B., Lercari, L. P., et al. (2004). Development of attentional networks in childhood. Neuropsychologia 42, 1029-1040. doi: 10.1016/j.neuropsychologia.2003.12.012

Skoe, E., and Kraus, N. (2012). A little goes a long way: how the adult brain is shaped by musical training in childhood. J. Neurosci. 32, 11507-11510. doi: 10.1523/JNEUROSCI.1949-12.2012

Thorell, L. B., Lindqvist, S., Bergman-Nutley, S., Bohlin, G., and Klingberg, T. (2009). Training and transfer effects of executive functions in preschool children. Dev. Sci. 12, 106-113. doi: 10.1111/j.1467-7687.2008.0 0745.x
Traverso, L., Viterbori, P., and Usai, M. C. (2015). Improving executive function in childhood: evaluation of a training intervention for 5-year-old children. Front. Psychol. 6:525. doi: 10.3389/fpsyg.2015.00525

Victorson, D., Manley, J., Wallner-Allen, K., Fox, N., Purnell, C., Hendrie, H. C., et al. (2014). Using the NIH Toolbox in special populations: considerations for the assessment of pediatric, geriatric, culturally diverse, non-English speaking and disabled individuals. Neurology 80(11 Suppl. 3), S13-S19. doi: 10.1212/WNL.0b013e3182872e26

Weibe, S. A., Sheffield, T., Nelson, J. M., Clark, C. A. C., Chevalier, N., and Espy, K. A. (2011). The structure of executive function in 3-year-olds. J. Exp. Child Psychol. 108, 436-452. doi: 10.1016/j.jecp.2010.08.008

Weintraub, S., Dikmen, S. S., Heaton, R. K., Tulsky, D. S., Zelazo, P. D., Bauer, P. J., et al. (2013). Cognition assessment using the NIH Toolbox. Neurology 80(11 Suppl. 3), S54-S64. doi: 10.1212/WNL.0b013e3182872ded

Zelazo, P. D., Anderson, J. E., Richler, J., Wallner-Allen, K., Beaumont, J. L., and Weintraub, S. (2013). NIH toolbox Cognitive Battery (CB): measuring executive function and attention. Monogr. Soc. Res. Child Dev. 78, 16-33. doi: $10.1111 /$ mono.12032

Zelazo, P. D., and Carlson, S. M. (2012). Hot and cool executive function in childhood and adolescence: development and plasticity. Child Dev. Perspect. 6, 354-360. doi: 10.1111/j.1750-8606.2012.00246.x

Conflict of Interest Statement: The authors declare that the research was conducted in the absence of any commercial or financial relationships that could be construed as a potential conflict of interest.

Copyright $(\odot) 2018$ Phillips-Silver and Daza. This is an open-access article distributed under the terms of the Creative Commons Attribution License (CC BY). The use, distribution or reproduction in other forums is permitted, provided the original author(s) and the copyright owner(s) are credited and that the original publication in this journal is cited, in accordance with accepted academic practice. No use, distribution or reproduction is permitted which does not comply with these terms. 